\title{
Diagnóstico do controle e perfil de sensibilidade de nematódeos de ovinos ao albendazol e ao levamisol no norte de Minas Gerais ${ }^{1}$
}

\author{
Eduardo R. Duarte ${ }^{2}$, Rayana B.Silva ${ }^{2}$, Viviane O. Vasconcelos ${ }^{2}$, Flávia A. Nogueira ${ }^{2}$ \\ e Neide J.F. Oliveira ${ }^{2}$
}

\begin{abstract}
Duarte E.R., Silva R.B., Vasconcelos V.O., Nogueira F.A. \& Oliveira N.J.F. 2012. [Diagnostic of the control and sensitivity profile of nematodes from sheep to albendazole and levamisole in northern Minas Gerais, Brazil.] Perfil de sensibilidade de nematódeos de ovinos ao albendazol e ao levamisol no norte de Minas Gerais. Pesquisa Veterinária Brasileira 32(2):147-152. Instituto de Ciências Agrárias, Universidade Federal de Minas Gerais, Campus Regional de Montes Claros, Av. Universitária 1000, Bairro Universitário, Montes Claros, MG 39404-006, Brazil. E-mail: duartevet@hotmail.com

The anthelmintic resistance is a major obstacle for the nematode control in ruminants and the presence of multiresistant nematodes could make impracticable the activity in a given area. The objective in this study was to evaluate the anthelmintic efficacy of albendazole and levamisole in sheep herds in northern Minas Gerais. The test was performed on ten farms, where we selected three groups of 12 lambs each. Two of these groups were respectively treated with levamisole $(5 \mathrm{mg} / \mathrm{kg})$ or albendazole $(10 \mathrm{mg} / \mathrm{kg})$. The third group did not receive treatment. Feces were collected at 0 and 7 day after treatment for the fecal egg reduction test. The nematode genus was evaluated with the identification of the larvae obtained from culture in the feces pre- and post-treatments. For all evaluated herds the levamisole showed high anthelminthic efficacy, which ranged from 90 to $100 \%$. Only for one herd, the albendazole was effective and for six farms, the efficacy of this drug was less than $80 \%$, considered insufficiently active. After the cultivation of larvae were identified mainly Haemonchus spp. and Trichostrongylus spp. The genus Haemonchus was the most prevalent even after treatment of sheep. It is emphasized the importance of in vivo efficacy tests for choosing anthelmintic drugs, since the susceptibility profile varied among sheep herds evaluated in this study.
\end{abstract}

INDEX TERM: Albendazole, levamisole, anti-helminthics, sheep, resistance, helminthosis, semiarid.

RESUMO.- A resistência anti-helmíntica é um dos principais entraves para o controle da verminose em ruminantes e a presença de nematódeos multiresistentes pode inviabilizar a atividade em uma determinada área. Neste trabalho o objetivo foi avaliar a eficácia anti-helmíntica do levamisol e do albendazol em rebanhos ovinos do norte de Minas Gerais. 0 teste foi realizado em dez propriedades, onde foram selecionados três grupos de 12 borregos cada. Dois desses grupos foram tratados respectivamente com levamisol (5 $\mathrm{mg} / \mathrm{kg} \mathrm{pc})$ ou albendazol ( $10 \mathrm{mg} / \mathrm{kg} \mathrm{pc})$ e o terceiro grupo não foi tratado. Fezes foram coletadas antes do tratamento

\footnotetext{
${ }^{1}$ Recebido em 1 de setembro de 2011.

Aceito para publicação em 13 de outubro de 2011.

${ }^{2}$ Instituto de Ciências Agrárias, Universidade Federal de Minas Gerais (UFMG), Caixa Postal 135, Avenida Universitária 1000, Bairro Universitário, Montes Claros, MG 39404-006, Brasil. *Autor para correspondência: duartevet@hotmail.com
}

e no sétimo dia após, para a realização do teste de redução de ovos por grama de fezes. Foi realizado o cultivo de larvas provenientes dos grupos avaliados para a identificação dos principais gêneros de nematódeos gastrintestinais antes e após os tratamentos. Para todos os rebanhos avaliados no norte de Minas Gerais, o levamisol apresentou eficácia anti-helmíntica elevada, variando de $90 \%$ a $100 \%$. Apenas para um rebanho o albendazol seria efetivo e para seis propriedades as eficácias dessa droga foram inferiores a $80 \%$, sendo considerada insuficientemente ativa. Após as coproculturas foram identificadas, em maior ocorrência, larvas dos gêneros Haemonchus e Trichostrongylus. $\mathrm{O}$ gênero Haemonchus foi o mais prevalente mesmo após o tratamento dos ovinos. Ressalta-se neste estudo a importância do teste de eficácia in vivo para a escolha das bases anti-helmínticas nas propriedades, pois foi observado que o perfil de susceptibilidade variou entre os diferentes rebanhos. 
TERMO DE INDEXAÇÃO: Albendazol, levamisol, anti-helmínticos, ovinocultura, resistência, verminose, semiárido.

\section{INTRODUÇÃO}

O Brasil possui boas condições climáticas para a produção de pequenos ruminantes. A ovinocultura é uma atividade econômica em crescimento na maioria dos estados brasileiros e esse fato está relacionado ao aumento do consumo da carne ovina. Além disso, a criação de ovinos surge como alternativa de viabilização social e econômica para pequenas e médias propriedades rurais (Cunha et al. 2007). 0 norte de Minas Gerais possui condições favoráveis à espécie ovina e apresenta grande potencial para se tornar um importante pólo produtor de pequenos ruminantes. Entretanto, os sistemas de criação predominantes são caracterizados por baixos índices zootécnicos, em consequência da precária nutrição e dos problemas sanitários dos animais (Geraseev et al. 2011).

0 principal entrave para o desenvolvimento dessa criação são as verminoses, que acometem ovinos em qualquer idade e sexo. Essas parasitoses prejudicam o desempenho, ocasionando perda de peso, reduzindo a fertilidade e ainda podem levar os animais ao óbito (Vieira et al. 2008). Haemonchus contortus, Trichostrongylus columbriformis, Strongyloides papillosus e Oesophagostomum colubianum são os nematódeos com maior prevalência e intensidade de infecção e são considerados os helmintos de maior impacto econômico para a exploração de pequenos ruminantes no Brasil (Vieira et al. 2008).

0 tratamento frequente do rebanho ovino com anti-helmínticos tem sido a única medida de controle das helmintoses gastrintestinais adotadas pelos criadores (Charles 1995). Esses produtos apresentam diferentes mecanismos de ação. Entretanto, poucas bases anti-helmínticas vêm sendo utilizadas no tratamento de nematódeos de pequenos ruminantes, dentre esses, os benzimidazóis, as avermectinas, os imidazotiazóis e as salicilanilicidas (Borges \& Rodrigues 2003, Coles 2005).

0 levamizol e o albendazol correspondem às bases mais frequentemente empregadas para o controle dessa enfermidade no Norte de Minas Gerais (Gerassev et al. 2011). Entretanto, a utilização indiscriminada dessas bases, associada às falhas de manejo, contribui para a seleção de cepas de helmintos resistentes (Amarante et al. 1992). A resistência anti-helmíntica é um dos principais problemas enfrentados no controle da verminose e, juntamente com as lesões diretas e indiretas ocasionadas pelas parasitoses, pode comprometer ou até mesmo inviabilizar essa atividade. 0 objetivo nesta pesquisa foi avaliar o controle e verificar a sensibilidade de nematódeos gastrintestinais a anti-helmínticos em diferentes rebanhos ovinos da região Norte de Minas Gerais.

\section{MATERIAL E MÉTODOS}

\section{Regiões de estudo}

0 experimento foi realizado em 10 propriedades localizadas em sete municípios na região norte de Minas Gerais: Montes Claros, Bocaiúva, Janaúba, Pirapora, Francisco Sá, Coração de Jesus e Januária (Quadro 1). Para a escolha das propriedades, além da localização geográfica, foram considerados a presença de rebanho ovino com número necessário de animais para os testes, facilidades de manejo e os animais não terem recebido tratamento com anti-helmínticos há, pelo menos, sessenta dias. As coordenadas geográficas dos respectivos municípios se encontram no Quadro 2.

Foram realizadas visitas nas propriedades rurais durante o período de maio de 2007 a agosto de 2010 e um questionário semiestruturado foi aplicado para os produtores com o objetivo de obter informações sobre o manejo e as medidas adotadas para o controle da verminose. As coletas foram realizadas nos meses da estação seca da região avaliada, quando os animais jovens estariam normalmente sendo tratados dentro do controle estratégico da verminose.

\section{Seleção dos animais}

Foram utilizados, em cada propriedade visitada, 36 borregos mestiços Santa Inês, com peso de 15-35 kg e naturalmente infectados por nematódeos gastrintestinais. Os critérios adotados para a seleção dos animais incluídos neste experimento foram o diagnóstico positivo para parasitos gastrintestinais pela contagem do número de ovos por grama de fezes (OPG) superior a 300. Essa contaminação mínima é requerida para melhor confiabilidade do teste de redução do OPG (Coles et al.,1992).

Os animais foram identificados com colares enumerados, foram pesados e divididos em três grupos de 12 animais, obtendo-se lotes com pesos, sexo e idade com distribuição homogênea. Grupo 1 foi tratado com $10 \mathrm{mg} / \mathrm{kg}$ de albendazol ${ }^{3}$, Grupo 2 foi tratado com $5 \mathrm{mg} / \mathrm{kg}$ de levamisol ${ }^{4}$, ambos por via oral com auxilio de seringas descartáveis e o Grupo 3 não recebeu tratamento anti-helmíntico. As doses utilizadas foram àquelas recomendadas pelos fabricantes de cada produto.

Os animais foram submetidos a período de jejum alimentar de aproximadamente 12 horas antes da administração dos vermífugos. Os procedimentos adotados foram aprovados pelo Comitê de

\section{Quadro 1. Distribuição e caracterização climática das propriedades avaliadas no norte de Minas Gerais}

\begin{tabular}{cllccc}
\hline Rebanho & Município & \multicolumn{1}{c}{ Mês /Ano } & P (mm) & Tơ & UR (\%) \\
\hline 1 & Montes Claros & Maio/2007 & 0,0 & 21,9 & 56 \\
2 & Bocaiúva & Maio/2009 & 5,4 & 21,4 & 69 \\
3 & Janaúba & Julho/2009 & 0,0 & 21,3 & 58 \\
4 & Janaúba & Julho/2009 & 0,0 & 21,3 & 58 \\
5 & Janaúba & Agosto/2009 & 0,2 & 22,4 & 52 \\
6 & Pirapora & Agosto/2009 & 0,2 & 22,4 & 52 \\
7 & Francisco Sá & Setembro/2009 & 48,4 & 25,5 & 54 \\
8 & Coração de Jesus & Setembro/2009 & 48,4 & 25,5 & 54 \\
9 & Montes Claros & Outubro/2009 & 23,9 & 25,2 & 66 \\
10 & Januária & Agosto/2010 & 0,0 & 20,9 & 47
\end{tabular}

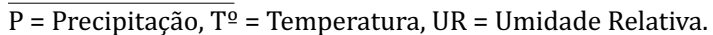

Fonte: Instituto Nacional de Meteorologia (INMET).

\section{Quadro 2. Coordenadas geográficas dos municípios avaliados no norte de Minas Gerais}

\begin{tabular}{lll}
\hline \multicolumn{1}{c}{ Cidade } & Latitude & Longitude \\
\hline Bocaiúva & $-17^{\circ} 06^{\prime} 28^{\prime \prime}$ & $43^{\circ} 48^{\prime} 54^{\prime \prime}$ \\
Coração de Jesus & $-16^{\circ} 41^{\prime} 07^{\prime \prime}$ & $44^{\circ} 21^{\prime} 54^{\prime \prime}$ \\
Francisco Sá & $-16^{\circ} 28^{\prime} 33^{\prime \prime}$ & $43^{\circ} 29^{\prime} 18^{\prime \prime}$ \\
Janaúba & $-15^{\circ} 48^{\prime} 09^{\prime \prime}$ & $43^{\circ} 18^{\prime} 32^{\prime \prime}$ \\
Januária & $-15^{\circ} 29^{\prime} 16^{\prime \prime}$ & $44^{\circ} 21^{\prime} 43^{\prime \prime}$ \\
Montes Claros & $-16^{\circ} 44^{\prime} 06^{\prime \prime}$ & $43^{\circ} 51^{\prime} 42^{\prime \prime}$ \\
Pirapora & $-17^{\circ} 20^{\prime} 42^{\prime \prime}$ & $44^{\circ} 56^{\prime} 31^{\prime \prime}$
\end{tabular}

Fonte: <http://www.apolo11.com/latlonphp?uf=mg> Acesso em 28 out. 2010 .

\footnotetext{
${ }^{3}$ Aldazol 10C0, Vallée S.A. - São Paulo, Av. Eng. Luís Carlos Berrini 716, 2oㅡㄴ andar, São Paulo, SP 04571-000.

${ }^{4}$ Ripercol L, Fort Dodge Saúde Animal Ltda, Rua Luiz Fernando Rodriguez 1701, V. Boa Vista, Campinas, SP 13064-798.
} 
Ética em Experimentação Animal da UFMG, aprovados no protocolo $42 / 2008$.

\section{Coletas de fezes e exames parasitológicos}

As amostras de fezes, com aproximadamente cinco a 15 gramas foram coletadas diretamente da ampola retal de cada animal, identificadas em sacos plásticos e mantidas em refrigeração para a determinação do número de ovos por grama de fezes (OPG) e para a obtenção das larvas. As coletas foram procedidas antes da vermifugação, no dia do tratamento e sete após o tratamento.

Realizaram-se a contagem de ovos por grama de fezes (OPG) pela técnica descrita por Gordon \& Whitlock (1939) e a croprocultura pela técnica descrita por Ueno (1995). Para a identificação das larvas utilizou-se a chave de Keith (1953), utilizando amostras de fezes antes e após os tratamentos. A eficácia dos produtos foi estimada segundo Coles et al.(1992);

\section{Eficácia $=(1-[\mathrm{OPGt} / \mathrm{OPGc}]) \times 100$}

OPGt = média do número de ovos por grama de fezes do grupo de animais tratados;

OPGc = média do número de ovos por grama de fezes do grupo de animais controle.

\section{Análises dos dados}

Os dados obtidos para cada propriedade foram avaliados em análise de variância, após transformação em $\log _{10}(O P G+10)$ e as médias comparadas pelo teste de Scott-Knott, com 5\% de significância, utilizando-se o pacote estatístico SAEG (2007).

A avaliação da eficácia dos fármacos utilizados baseou-se na determinação proposta pelo Grupo Mercado Comum (GMC) para anti-helmínticos, sendo altamente efetivo quando reduz mais que 98\% do OPG, efetivo com 90-98\%, moderadamente efetivo com 80$89 \%$ e insuficientemente ativo com menos que $80 \%$ de redução e não registrável (GMC 1996). As frequências dos gêneros de nematódeos foram comparadas pelo teste do qui-quadrado, com nível de significância de 5\%, utilizando-se o pacote estatístico SAEG (2007).

\section{RESULTADOS E DISCUSSÃO Caracterização dos rebanhos ovinos das propriedades avaliadas}

Durante o período avaliado, a precipitação média esteve entre zero a $323,9 \mathrm{~mm}$ mensais e as médias dos meses para a temperatura e a umidade relativa variaram de 20,9 a $25,5^{\circ} \mathrm{C}$ e 47 a $69 \%$, respectivamente. A região avaliada apresentou características de clima semiárido e as coletas foram concentradas durante a estação seca (maio a setembro). Nesse período, a população de parasitos na pastagem é baixa ou quase nula, sendo encontrado em maior concentração de nematódeos adultos nos animais (Nogueira et al. 2009).

0 tipo de exploração predominante nas propriedades avaliadas era o extensivo, onde os animais eram abrigados em galpões ou apriscos. Os produtores dedicavam-se à criação de ovinos de corte, com grau racial predominante da raça Santa Inês. A identificação zootécnica dos animais era realizada em $50 \%$ das propriedades e os produtores das propriedades um, quatro, cinco, seis e 10 não adotavam vermifugação estratégica. As médias do OPG inicial dos rebanhos de cada propriedade estão demonstradas no Quadro 3.

No rebanho da propriedade seis, os animais eram vermifugados com anti-helmintico a base de ivermectina há aproximadamente um ano e meio. Essa prática provavel-
Quadro 3. Contagem média de ovos por grama de fezes (OPG) nos rebanhos testados e a porcentagem dos gêneros de nematóides identificados nas coprocultura antes dos tratamentos

\begin{tabular}{ccccccc}
\hline Propriedades & OPG (dia 0) & Haem. & Trich. & Oeso. & Coop. & Strong. \\
\hline 1 & $773,21 \mathrm{c}$ & - & 100,00 & - & - & - \\
2 & $1060,00 \mathrm{~b}$ & 65,08 & 32,52 & 2,40 & - & - \\
3 & $1373,61 \mathrm{a}$ & 47,95 & 41,18 & 10,87 & - & - \\
4 & $589,70 \mathrm{c}$ & 91,73 & 8,27 & - & - & - \\
5 & $350,00 \mathrm{c}$ & 66,85 & 33,15 & - & - & - \\
6 & $3255,71 \mathrm{a}$ & 92,27 & 7,73 & - & - & - \\
7 & $1487,09 \mathrm{~b}$ & 100,00 & - & - & - & - \\
8 & $993,10 \mathrm{~b}$ & 95,55 & 2,83 & - & 1,62 & - \\
9 & $934,61 \mathrm{~b}$ & 72,32 & 12,72 & 0,50 & 12,96 & 1,50 \\
10 & $855,76 \mathrm{~b}$ & 93,60 & 6,40 & - & - & - \\
Média Geral & 1167,27 & 80,43 & 16,06 & 1,53 & 1,82 & 0,16
\end{tabular}

Haem. = Haemonchus spp., Trich. $=$ Trichostrongylus spp., Oeso. $=O e-$ sophagostomum spp., Coop. = Cooperia spp., Strong. = Strongylus spp., (-) ausente. Médias seguidas pela mesma letra na coluna não diferem estatisticamente entre si pelo teste de média Scott-Knott a 5\% de probabilidade.

mente poderia propiciar a seleção e o aparecimento de resistência anti-helmintica, comprometendo o controle da verminose na propriedade, uma vez que a maior contaminção de ovos de nematódeos foi obsevada para essa propriedade. 0 principal mecanismo de instalação da resistência ocorre pelo uso frequente e continuo da mesma base farmacológica destinada ao controle dos parasitas, quando isso ocorre os indivíduos sobreviventes são capazes de suportar qualquer esquema de tratamento e assim contaminam a pastagem com novas e vigorosas populações de nematódeos resistentes (Prichard 1994).

Os rebanhos das propriedades um, quatro e cinco apresentaram as menores média de OPG inicial. A propriedade do rebanho um, durante o ano de 2007 recebeu assistência técnica em ação de extensão, quando diagnosticou-se os principais problemas relacionados ao manejo alimentar e sanitário, propondo-se recomendações técnicas como o controle estratégico. Somente este rebanho promovia a separação das matrizes no periparto e vemifugava esses animais nesse período. Segundo Amarante et al. (1995) na ovinocultura, as categorias mais susceptíveis aos efeitos do parasitismo são os cordeiros desmamados e as ovelhas no periparto. Nesse período é fundamental o controle tático das matrizes, uma vez que o OPG aumenta significativamente, favorecendo a contaminação das pastagens e infecções dos borregos com larvas infectantes (Vieira et al. 2008, Nogueira et al. 2009).

Na propriedade do rebanho quatro, o sistema de pastejo era rotacionado, com área de 30 hectares de pastagem. No ano anterior o proprietário vendeu parte do rebanho, dessa forma, os animais eram manejados com baixa taxa de lotação. Apesar dessa prática não ser economicamente viável a longo prazo, a contaminação dos animais por nematódeos pode reduzir de forma significava, quando são criados com baixas densidades (Ramos et al. 2004).

No rebanho cinco, a menor media de OPG pode estar relacionada com as instalações e o manejo da propriedade. 0 aprisco era suspenso a uma altura média de $1,5 \mathrm{~m}$ do solo e a higiene era realizada semanalmente. Além disso, apenas para essa propriedade os animais eram separados por cate- 
goria, esse manejo evita que os animais mais velhos contaminem os mais jovens, dessa forma proporcinando uma carga parasitária menor nos borregos. Para o controle da verminose, uma das principais medidas a ser observada é a separação por faixa etária, pois os animais jovens são mais suscetíveis às verminoses do que os adultos (Nogueira et al 2009).

Após o cultivo e identificação das larvas provenientes dos animais dessas propriedades, observou-se a maior ocorrência do gênero Haemonchus para os rebanhos dois, quatro, cinco, seis, sete, oito, nove e $10(\mathrm{p}<0,01)$. Para o rebanho três, a frequência de Haemonchus spp. e Trichostrongylus spp. foram semelhantes $(\mathrm{p}>0,05)$. Especificamente para o rebanho um, observou-se que $100 \%$ das larvas L3 correspondiam ao gênero Trichostrongylus, sugerindo uma possível seleção por uso constante de anti-helmíntico (Quadro 3). Em pesquisa realizada no município de Francisco Sá, também localizado no Norte de Minas Gerais, observou-se o predomínio de Trichostrongylus spp. em relação a Haemonchus spp., correspondendo a 51,4 e $26,4 \%$ das larvas identificadas em coproculturas realizados durante o período seco do ano, respectivamente (Nogueira et al. 2009).

\section{Eficácia anti-helmíntica do levamizol e do albendazol}

Constatou-se redução na contagem do OPG dos animais tratados em relação ao grupo controle para todas as propriedades avaliadas. 0 percentual de eficácia variou de 90 a $100 \%$ para animais tratados com levamisol e de 56,3$100 \%$ para os borregos vermifugados com albendazol. 0 levamisol foi mais efetivo $(\mathrm{p}<0,05)$ para a redução da média do OPG de nove rebanhos avaliados (Quadro 4).

Neste trabalho pôde-se observar, portanto, que o albendazol apresentou menor eficácia, verificando assim, uma possível resistência, pois a eficácia para nove rebanhos foi inferior a 90\%. Para seis desses rebanhos, essa base apresentou eficácias inferiores a $80 \%$, sendo considerada insuficientemente ativa (GMC 1996). Esse resultado poderia ser justificado uma vez que, para os rebanhos avaliados, utilizava-se mais recentemente o albendazol e os produtores trocavam somente o produto comercial e essa base anti-helmintica era mantida.

Quadro 4. Média do número de ovos por grama de fezes (OPG) de grupos de ovinos após os tratamentos e eficácia de drogas anti-helmínticas em diferentes rebanhos ovinos no Norte de Minas Gerais

\begin{tabular}{cccccc}
\hline $\begin{array}{c}\text { Propri- } \\
\text { eades }\end{array}$ & $\begin{array}{c}\text { Controle } \\
\text { OPG }\end{array}$ & $\begin{array}{c}\text { Levamisol } \\
\text { OPG }\end{array}$ & $\begin{array}{c}\text { Eficácia } \\
(\%)\end{array}$ & $\begin{array}{c}\text { Albendazol } \\
\text { OPG }\end{array}$ & $\begin{array}{c}\text { Eficácia } \\
(\%)\end{array}$ \\
\hline 1 & $773,21^{\mathrm{a}}$ & $7,14^{\mathrm{c}}$ & 99,1 & $83,30^{\mathrm{b}}$ & 89,2 \\
2 & $1060,0^{\mathrm{a}}$ & $10,00^{\mathrm{c}}$ & 99,5 & $235,7^{\mathrm{b}}$ & 77,7 \\
3 & $3373,61^{\mathrm{a}}$ & $1,13^{\mathrm{c}}$ & 99,9 & $386,36^{\mathrm{b}}$ & 88,5 \\
4 & $589,70^{\mathrm{a}}$ & $62,00^{\mathrm{c}}$ & 90,0 & $159,09^{\mathrm{b}}$ & 73,0 \\
5 & $350,00^{\mathrm{a}}$ & $18,19^{\mathrm{c}}$ & 94,8 & $72,73^{\mathrm{b}}$ & 79,2 \\
6 & $3255,71^{\mathrm{a}}$ & $104,55^{\mathrm{c}}$ & 96,8 & $594,83^{\mathrm{b}}$ & 81,7 \\
7 & $1531,25^{\mathrm{a}}$ & $30,77^{\mathrm{c}}$ & 98,0 & $450,00^{\mathrm{b}}$ & 70,6 \\
8 & $993,10^{\mathrm{a}}$ & $0,00^{\mathrm{b}}$ & 100,0 & $0,00^{\mathrm{b}}$ & 100,0 \\
9 & $934,61^{\mathrm{a}}$ & $93,18^{\mathrm{c}}$ & 90,1 & $408,30^{\mathrm{b}}$ & 56,3 \\
10 & $855,76^{\mathrm{a}}$ & $16,67^{\mathrm{c}}$ & 98,6 & $344,44^{\mathrm{b}}$ & 59,8 \\
Média Geral & $1371,69^{\mathrm{a}}$ & $34,36^{\mathrm{c}}$ & & $\mathbf{2 7 3 , 4 8 ^ { \mathrm { b } }}$ & \\
\hline
\end{tabular}

Médias seguidas por letras diferentes na linha diferem estatisticamente entre si pelo teste de Scott-Knott a 5\% de probabilidade.Coeficiente de variação (CV): 30,88\%.
No presente trabalho, apenas o rebanho oito apresentou eficácia de $100 \%$ para ambas as bases avaliadas e esse resultado pode estar relacionado com o manejo empregado anteriormente, pois nessa propriedade os animais não recebiam qualquer tratamento anti-helmíntico a aproximadamente um ano. Dessa forma, a pressão de seleção por anti-helmínticos seria menor.

Os dados deste estudo corroboraram com as pesquisas de Melo et al. (2003) e Lima et al. (2010) que reportam eficácia anti-helmítinca do levamisol superior a 90\% para ovinos criados no estado do Ceará e Pernambuco, respectivamente.

Santos e Gonçalves (1967) descreveram no Rio Grande do Sul, o primeiro caso de resistência anti-helmíntica em ovinos no Brasil. Atualmente, existem vários relatos de resistência, como reportaram Melo et al. (2004) na região do baixo e médio Jaguaribe, no Ceará, e o problema está sendo constatado em todo país.

Relatos de resistência anti-helmíntica também foram observados nos criatórios ovinos na região sul do Brasil, com casos de resistência às classes de benzimidazóis, imidatiazóis e ivermectinas (Farias 1997). No Paraná, Souza et al. (1997) verificaram, em 25 rebanhos ovinos, que a resistência anti-helmíntica estava presente em 92,3\% dos rebanhos testados para oxfendazol, em $80 \%$ para levamisol, em $85,7 \%$ para o tetramisol; em $91,3 \%$ para ivermectina, em $30,8 \%$ para moxidectina e em $85,8 \%$ para o closantel. No Rio Grande do Sul, Echevarria et al. (1996) indicaram que aproximadamente $90 \%$ dos rebanhos apresentam nematódeos resistentes aos benzimidazóis, 84\% ao levamisol, $20 \%$ ao closantel e $13 \%$ a ivermectina. Buzzulini et al. (2007) também encontraram resistência a moxidectina em um rebanho em Jaboticabal, São Paulo. No Estado do Mato Grosso do Sul, Sczesny-Moraes et al. (2010) encontraram resistência a ivermectina e albendazol em rebanhos de ovinos.

Considerando a situação atual, é possível reportar que existe tendência de aumento nos níveis de resistência, pela persistência do uso da base albendazol em virtude da cultura dos criadores em atribuir a essa droga uma alta eficiência, facilitada pela redução do preço das formulações comerciais e por muitas vezes trocar apenas o nome comercial do vermífugo, promovendo o uso prolongado desse mesmo princípio ativo (Sczesny-Moraes et al. 2010).

\section{Gêneros de nematódeos gastrintestinais identificados após os tratamentos anti-helmínticos}

Após o cultivo de fezes dos animais tratados com os anti-helmínticos, os gêneros identificados foram Haemonchus, Trichostrongylus, Strongyloides, Oesophagostomun e Cooperia spp. (Quadro 4). Para os rebanhos nove e 10, que apresentaram eficácia anti-helmintica inferior a $60 \%$ para o albendazol (Quadro 4), o gênero Haemonchus foi o de maior ocorrência $(\mathrm{p}<0,01)$, correspondendo, respectivamente, a 79,3-88,9\% das larvas identificadas. Os rebanhos dois e sete apresentaram $100 \%$ de ocorrência para esse gênero nas coproculturas de animais tratados com albendazol, que também promoveu baixa eficácia anti-helmintica nessas propriedades. Especificamente para o rebanho sete, observou-se também 100\% 
Quadro 5. Percentual de larvas de helmintos provenientes de rebanhos ovinos no norte de Minas Gerais após o tratamento com anti-helmíntico

\begin{tabular}{|c|c|c|c|c|c|c|c|c|c|c|}
\hline \multirow[t]{2}{*}{ Propriedades } & \multicolumn{5}{|c|}{ Albendazol } & \multicolumn{5}{|c|}{ Levamisol } \\
\hline & Haem. & Trich. & Oeso. & Coop. & Strong. & Haem. & Trich. & Oeso. & Coop. & Strong. \\
\hline 1 & - & 100,0 & - & - & - & - & - & - & - & - \\
\hline 2 & 100,0 & - & - & - & - & - & - & - & - & - \\
\hline 3 & 86,8 & 11,8 & 1,4 & - & - & 36,5 & 60,2 & 3,3 & - & - \\
\hline 4 & 84,7 & 15,3 & - & - & - & 84,1 & 15,9 & - & - & - \\
\hline 5 & 94,2 & 5,8 & - & - & - & 76,0 & 24,0 & - & - & - \\
\hline 6 & 98,8 & 3,2 & - & - & - & 64,9 & 35,1 & - & - & - \\
\hline 7 & 100,0 & - & - & - & - & 100,0 & - & - & - & - \\
\hline 8 & - & - & - & - & - & - & - & - & - & - \\
\hline 9 & 79,3 & 9,0 & 0,5 & 10,7 & 0,5 & 5,7 & 92,8 & 0,5 & 1,0 & - \\
\hline 10 & 88,9 & 11,1 & - & - & - & 76,9 & 23,1 & - & - & - \\
\hline Médias & 81,4 & 6,8 & 0,4 & 1,3 & 0,1 & 49,4 & 27,9 & 0,4 & 0,1 & 0 \\
\hline
\end{tabular}

Haem. = Haemonchus spp., Trich.= Trichostrongylus spp., Oeso. = Oesophagostomum spp., Coop. = Coope-

ria spp., Strong. = Strongylus spp., (-) ausente.

de ocorrência desse nematódeo para os animais medicados com levamisol. Esses dados são importantes, pois já indicam uma possível seleção de populações monoespecíficas de nematódeos gastrintestinais à essas bases e, possivelmente, resistentes a esses vermífugos. Para o rebanho um que anteriormente ao tratamento, apresentou monoinfecção por Trichostrongylys spp. (Quadro 3), após a administração de albendazol observou-se que esse gênero foi o único a ser identificado nas coproculturas. Entretanto, para os animais desse rebanho tratados com levamisol, a eficácia anti-helmíntica foi superior a 99\% e as larvas não se desenvolveram nas coproculturas (Quadro 5).

A predominância do parasitismo por Haemonchus sp. e Trichostrongylus sp. relatada neste estudo, foi semelhante à descrita por Kawano et al. (2001) e Ramos et al. (2004). Esses autores descrevem também que nematódeos do gênero Haemonchus apresentaram altos índices de resistência para albendazol e ivermectina. Entretanto, com relação a Trichostrongylus sp. os mesmos autores identificaram $100 \%$ de sensibilidade do gênero à ivermectina e closantel e $44 \%$ de resistência ao levamisol.

Resistência a outras bases também tem sido constatada no Brasil. Falbo et al. (2009) registraram pela primeira vez a ocorrência de resistência de $H$. contortus ao closantel em cordeiros na área central do Paraná. No estado do Mato Grosso do Sul, Sczesny-Moraes et al. (2010) detectaram resistência dos gêneros Haemonchus, Trichostrongylus, Cooperia e Oesophagostomum às bases farmacológicas albendazol, ivermectina, levamisole, triclorfon, moxidectina, closantel e à associação entre albendazol, ivermectina e levamisol, em maior ou menor intensidade, sendo o gênero Haemonchus o mais resistente. Esses autores reportaram também um caso de resistência múltipla nesse estado. Rosalinski-Moraes (2007), identificaram 100\% de cepas resistentes de Haemonchus sp. à ivermectina, porém sensíveis a albendazol e ao levamisol. Melo et al. (2005), Lima et al. (2010) e Barbosa et al. (2004) identificaram Haemonchus spp. e Trichostrongylus spp. como os gêneros que apresentaram os maiores índices de resistência aos anti-helmínticos nos estados do Ceará, Pernambuco e Minas Gerais, respectivamente.

Esses resultados, somados aos observados nesta pesquisa, demonstraram que Haemonchus spp. Foi o nemató- deo com maior ocorrência e que apresentou maior índice de resistência aos anti-helmínticos testados. Segundo Coles (2005) Haemonchus contortus apresenta o mais rápido estabelecimento da resistência, em consequência da grande variabilidade genética e pelo elevado potencial biológico.

Nos rebanhos dois e oito não foram encontradas larvas de helmintos após o cultivo de larvas provenientes de borregos tratados com levamisol, o que está diretamente relacionado à alta eficácia dessa base para esses rebanhos, correspondendo a 99,5 e 100\%, respectivamente.

\section{CONCLUSÕES}

Houve grande variação na contagem inicial do OPG entre os rebanhos avaliados, que poderia estar relacionada com as diferenças de manejo e instalações presentes nos criatórios. A média do OPG nos rebanhos do norte de Minas Gerais foi alta, o que poderia ocasionar menor desenvolvimento dos animais e prejuízos econômicos aos produtores.

Os gêneros mais frequentes foram Haemonchus e Trichostrongylus. A administração de levamisol foi eficaz na redução do OPG para todas as propriedades avaliadas. As eficácias dessa base foram significativamente maiores, quando comparadas àquelas observadas para o albendazol, para nove rebanhos avaliados.

Os dados obtidos enfatizam a importância do teste de redução do OPG para escolha das bases anti-helmínticas, uma vez que o perfil de susceptibilidade variou entre as diferentes propriedades avaliadas no norte de Minas Gerais.

Agradecimentos.- Conselho Nacional de Desenvolvimento Científico e Tecnológico (CNPq), à Fundação de Amparo à Pesquisa do Estado de Minas Gerais (Fapemig) e ao Banco do Nordeste do Brasil (Fundeci) pelo apoio financeiro do projeto. Às Pro-Reitorias de Extensão e Graduação da Universidade Federal de Minas Gerais.

\section{REFERÊNCIAS}

Amarante A.F.T., Barbosa M. A., Oliveira M. A.G., Carmello M.J. \& Padovani C.R. 1992. Efeito da administração de oxifendazol, ivermectina e levamisol sobre os exames coproparasitológicos de ovinos. Braz. J. Vet. Res. Anim. Sci. 29:31-38.

Amarante A.F.T. \& Barbosa M.A. 1995. Seasonal variation in populations of infective larvae on pasture and nematode feacal egg output in sheep. Veterinária e Zootecnia 7:127-133. 
Barbosa F.C., Luiz L.I., Teixeira T.C.S. \& Amorim L.L. 2004. Eficácia do sulfóxido albendazole e closantel no controle da verminose em caprinos. Revta Bras. Parasitol. Vet. 13:268.

Borges C.C. L. \& Rodrigues A.B. 2003. Atividade in vitro de anti-helmínticos sobre larvas infectantes de nematódeos. Parasitol. Latinoamericana 58:142-147.

Buzzulini C., Silva Sobrinho A.G., Costa A.J., Dos Santos T.R., Borges F.A. \& Soares V.E. 2007. Eficácia anti-helmíntica comparativa da associação albendazole, levamisole e ivermectina a moxidectina em ovinos. Pesq. Agropec. Bras. 42(6):891-895.

Charles T.P. 1995. Disponibilidade de larvas infectantes de nematódeos gastrointestinais parasitas de ovinos deslanados no semi-árido pernambucano. Ciência Rural 25:437-442.

Coles G.C. 2005. Anthelmintic resistance - Looking to the future: a perspective. Res. Vet. Sci. 78:99-108.

Coles G.C., Bauer C., Borgsteede F.H., Geerts S., Klei T.R., Taylor M.A. \& Waller P.J. 1992. World Association for the Advancement of Veterinary Parasitology (WAAVP) methods for the detection of anthelmintic resistance in nematodes of veterinary importance. Vet. Parasitol. 44:35-44.

Cunha E.A., Santos L.E., Bueno M.S. \& Veríssimo C.J. 2007. Produção de ovinos para corte. Instituto de Zootecnia, Nova Odessa, p.141.

Echevarria F.A.M., Borba M.F.S., Pinheiro A.C., Waller P.J. \& Hansen J.W. 1996. The prevalence of anthelmintic resistance in nematode parasites of sheep in southern Latin-America: Brazil. Vet. Parasitol. 62:199-206

Falbo M.K, Soccol V.T., Sandini I.E., Neumann M. \& Ishiy T.M. 2009. Atividade anti-helmíntica do triclorfon e closantel em cordeiros naturalmente infectados por Haemonchus sp. Ciênc. Anim. Bras. 10(3):926-930.

Farias M.T. 1997. A survey on resistance to anthelmintics in sheep stud farms of southern Brazil. Vet. Parasitol. 72(2):209-214.

Geraseev L.C., Duarte, E.R., Almeida, A.C., Teixeira, L.M. \& Morais G. 2010. Perfil de propriedades de ovinos e caprinos no Norte de Minas e recomendações técnicas, p.696-712. In: Ciência e Tecnologia na Pecuária de Caprinos e Ovinos. Vol.1. Fortaleza, CE.

Gordon H.M.L. \& Whitlock H.N. 1939. A new technique for counting nematode egg in sheep faeces. J. Council Sci. Industry Res. Australia 12(1):50-52.

GMC - Grupo Mercado Comum 1996. Regulamento Técnico para Registros de Produtos Antiparasitários de Uso Veterinário. Decisão no.4/91, Resolução no.11/93. Mercosul, Resolução no.76/96.

Kawano E.L., Yamamura M.H. \& Ribeiro E.L.A. 2001. Efeitos do tratamento com anti-helmíntico em cordeiros naturalmente infectados com helmin- tos gastrintestinais sobre os parâmetros hematológicos, ganho de peso e qualidade da carcaça. Arq. Fac. Vet., UFRGS, 29(2):113-121.

Keith R.K. 1953. The differentiation of the infective larvae of some common nematode parasites of cattle. Aust. J. Zool. 1:.223-235.

Lima M.M., Farias M.P.O., Romeiro E.T., Ferreira D.R. A. \& Alves L.C. \& Faustino M.A.G. 2010. Eficácia da moxidectina, ivermectina e albendazole contra helmintos gastrintestinais em propriedades de criação caprina e ovina no estado de Pernambuco. Ciênc. Anim. Bras. 11:94-100.

Melo A.C.F.L., Reis I.F., Belivaqua C.M.I., Vieira I.S. \& Echevarria F.A. 2003. Nematódeos resistentes a anti-helmínticos em rebanhos de ovinos e caprinos do estado do Ceará, Brasil. Ciência Rural 33:339-344.

Melo A.C.F..L., Rondon F.C.M., Reis I.F. \& Bevilaqua C.M.L. 2004. Desenvolvimento da resistência ao oxfendazol em propriedades rurais de ovinos na região do Baixo e Médio Jaguaribe, Ceará, Brasil. Revta Bras. Parasitol. Vet. 13(4):137-141.

Nogueira F.A., Rocha F.T., Ribeiro G.C., Silva N.O., Geraseev L.C., Almeida A.C. \& Duarte E.R. 2009. Variação sazonal da contaminação por helmintos em matrizes ovinas e borregos submetidos a controle integrado e criados em pastagens tropicais. Ciência. Rural 39:2544-2549.

Prichard R.K. 1994. Antihelmintic resistance. Vet. Parasitol. 54:256-268

Ramos C.L., Bellato V., Souza A.P., Ávila V.S., Coutinho G.C. \& Dalagnoll C.A. 2004. Epidemiologia das helmintoses gastrintestinais de ovinos no Planalto Catarinense. Ciência Rural 34(6):1889-1895.

Rosalinski-Moraes F., Moretto L.H., Bresolin W.S., Gabrielli I., Kafer L., Zanchet I.K., Sonaglio F. \& Thomaz-Soccol V. 2007. Resistência anti-helmíntica em rebanhos ovinos da região da Associação dos Municípios do Alto Irani (AMAI), Oeste de Santa Catarina. Ciênc. Anim. Bras. 8(3):559-565.

Santos V.T. \& Gonçalves P.C. 1967. Verificação de estirpes resistentes de Haemonchus contortus resistente ao thiabendazole no Rio Grande do Sul (Brasil). Revta Fac. Agron. Vet., Porto Alegre, 9:201-209.

Sczesny-Moraes E.A, Bianchin I., Silva K.F., Catto J.B., Honer M.R. \& Paiva F. 2010. Resistência anti-helmíntica de nematopides gastrointestinais em ovinos, Mato Grosso do Sul. Pesq. Vet. Bras. 30(3):229-236.

Souza F.P. \& Thomas-Soccol V. 1997. Contribuição para o estudo da resistência de helmintos gastrointestinais de ovinos (Ovis aries) aos anti-helmínticos, no Estado do Paraná. Revta Bras. Parasitol. Vet. 6:217.

Ueno H. 1995. Cultivo quantitativo de larvas de nematódeos gastrintestinais de ruminantes com tentativa para pré-diagnóstico. JICA, Salvador, p.138.

Vieira L.S. 2008. Métodos alternativos de controle de nematóides gastrintestinais em caprinos e ovinos. Tecnol. Ciênc. Agropec. 2:49-56. 